\title{
TEACHING AND LEARNING FOREIGN LANGUAGES WITH ICT
}

\author{
Alina NEGOESCU \\ alina.negoescu@yahoo.com \\ Simona BOŞTINĂ-BRATU \\ mbostinabratu@yahoo.fr
}

“NICOLAE BĂLCESCU” LAND FORCES ACADEMY, SIBIU, ROMANIA

\begin{abstract}
The use of information and communication technologies (ICT) in teaching and learning foreign languages has risen sharply among the educational community. Teachers access and implement innovations without always realizing their full implications for them and their students. However, this is not necessarily a negative thing, because if no one used innovations, little progresses would be made and there would be nothing to evaluate. The article presents certain features of ICT that can be used to good advantage in a rich learning environment, and the use of video as an ICT tool in the foreign language class. The paper also discusses the role of the teacher in implementing technologies and we argue that it is the teacher, not the technology who determines the quality of the learning and teaching. There are people who are afraid that the teacher's role would be compromised if we integrate information communication technologies in education; however we militate for a 'techno-humanistic' system, in which teachers, learners and technology would form a lasting meaningful alliance.
\end{abstract}

\section{KEYWORDS:}

ICT, video, teacher, benefits and challenges

\section{Introduction}

Technology has become an expected literacy in higher education and in our society, a universal language spoken worldwide, regardless of the profession (Marcinek, 2014). Trying to keep up with 
the requirements of current society and to take advantage of the advances in technology, teachers all over the world implement information communication technologies (ICT) in the classroom in order to deliver content effectively and address students' needs. Computer based instruction already occupies an increasing role in teaching foreign languages. We are not a big fan of technology nor are we very skilled in using it, but we have to admit that technology greatly enhances teaching and learning foreign languages. However, we should not forget that teaching and learning are social processes and require communication between teacher and learners; therefore technology facilitates but does not replace these social processes (Bates \& Poole 2003).

Since ICT is obviously an enormous topic I will narrow the focus of this article to two main points. First the paper begins by defining ICT and what it encompasses and certain features of ICT as well as benefits and challenges of using it in the classroom. Then it discusses the use of videos to engage students and the teacher's role in integrating technology.

\section{Information Communication Technologies}

ICT stands for information communication technologies and comprises a set of technological tools and resources used to communicate and also to create, disseminate, store and manage information. In the classroom, technologies can include all kinds of tools from computers and internet to broadcasting technologies and telephony (https://en.wikibooks.org/wiki/ ICT_in_Education/Definition_of_Terms).

Therefore under the big umbrella of ICT there are many tools that we can include such as the projector, presentation software (PowerPoint and Prezi), videos, conference tools (Skype), blogs (www.edmondo.com, www.wordpress.com), wiki (www.wikispace.com), online dictionaries, interactive books, interactive whiteboard, learn English websites (http://learnenglish.britishcouncil.org/en/), Google, YouTube and even video games.
Originally it was all about how teachers presented the information using the copy machine, tape recorder, VCR, and others, but now it's about the way teachers and students access information and transforms via technology active learning into interactive learning by sharing ideas, collaborating with colleagues or even creating videos. The textbook is not sufficient anymore, teachers need to bring it alive by adapting it and provide supplemental resources. We can achieve this by modifying the content (create visual pictures, change the dialog), simplifying the content, reviewing the content (make games, quizzes, slideshows) and supplementing the content with online games, flashcards, songs and videos, etc. (Korlotyan, 2015). "Since nowadays' society requires students to be able to confront a multitude of complex situations, the traditional education based solely on the transmission of knowledge is no longer sufficient" (Mihăilă-Lică, Fleischer \& Palea, 2015).

However, introducing technology is an overwhelming task for anyone trying to select the best tools while considering the goals for student learning too. Yet, technology is integrated in almost every aspect of our life and every job, so educators must find a balance between technology usage and offline socializing and interpersonal skills (Marcinek, 2014).

It takes a lot of time and work to master a language and obviously there is not enough time in class for that, so language educators should motivate students and teach them how to access knowledge and data from around the world in order to become independent learners. We can do that by letting them know what is available and good on the internet, providing online access to our teaching materials and also by sharing with students in an online environment and communicate with native speakers (Korlotyan, 2015).

Alan Pritchard (2007) enumerates certain widely agreed features of ICT with big impact in teaching and learning, such as speed, capacity, communicability, interactivity, non- 
linearity and multi-modality. ICT enables actions and interactions to be undertaken remarkably quickly, for instance messages can be sent and the replies can came back in minutes or even seconds. The capacity of internet is enormous providing access to an incredible large amount of information.

It also provides means of communicating both within the classroom and beyond. Interactivity is a key feature and also a big advantage of ICT, considering the interactive computer applications, and the mediated communication. Clearly, the vast amount of information available on the internet can be explored in many ways according to one's own interests. Multimodality implies sounds, pictures and texts, and it is well known that we learn better if there are more senses involved in the process of learning.

Michael Romano (2003) argues that there is a growing number of students who are less motivated, less interested and less engaged in the process of learning. He also mentions that the left-brain dominant students, those who work better with words, are clearly advantaged compared to the right-brain dominant students who respond better to pictures. The left-brain dominant are advantaged by our educational system because they respond well to the verbal, linear styles of teaching. However, technology, through multimodality, would also support the right-brain dominant students. Thus, "a whole-brain, Digital Age model of education" is proposed. Teachers "empowered with technology" could make the classes as interesting and as attractive as what happens in the world beyond the walls of the classroom.

Now that we know the meaning and certain characteristics if ICT, I would like to highlight some of the benefits and challenges of using technologies in the foreign language class.

When integrated effectively technologies provide substantial benefits in teaching and learning foreign languages. Technologies enrich the content (photos, videos, PowerPoint); make the delivery of the content more interactive by using interactive whiteboards for example; and enable repetition and adaptability of the content. With the aid of technologies teachers provide students authentic audio and video of the target culture and up to date materials in order to engage students. In addition to engage students in class, the adequate use of technologies enhances classroom communication and interconnectivity and offer students the opportunity to communicate, collaborate, and interact with course material in different ways (http://cte.cornell.edu/teaching-ideas/ teaching-with-technology/video.html).

Although technology integration has many benefits, there are also challenges. Sometimes students encounter problems regarding the use of the online learning software, especially the lack of the direct contact with the teacher (Dragomir, Niculescu \& Poşa, 2014). Romano (2003), who greatly supports the implementation of technology in the classroom, enumerates six barriers to the effective use of technology. First and most important is the fact that there is no common, coherent vision on how technology should be used in the classroom and then some teachers perceive technology as a threat to their professional security rather than a tool that would enhance the teaching and learning process. A third barrier would be the fact that people at the highest level have misconceptions regarding the way teachers would adapt technology in the classroom. The fourth challenge regards technology integration into the curriculum and the fifth relates to inadequate use of technology and not analysing the failures. The last barrier addresses leaders in education who lack a comprehensive understanding of the effective use of technology in the teaching and learning process.

Other challenges refer to the lack of resources such as interactive whiteboards, computers connected to internet for every student, video projectors and screens. Nevertheless, technology itself is not as important as the way we exploit it. If there aren't computers for every student in the 
classroom, the teacher can record a video with her/him explaining/present certain topics and share it with the students, who can watch it at home. Students can also share their assignments, projects or presentation with the teacher and the other colleagues and they can even peer review each other's work. We can all watch the videos and discuss good aspects or the less satisfactory aspects of their presentations. Thus, we extend the teaching and learning environment outside the class and make it more interactive.

No doubt interactivity can also be achieved simply by using the blackboard, the chalk and some paper. Sometimes less is more. Class discussions and debates can get very lively, the same as an activity of matching badges with cards of military ranks, and then creating a mobile diagram and discussing it and trying to find equivalents with ranks from other countries can engage students in the process of learning. Also, role plays and word competitions have a positive impact on students. Therefore, we should not use technology only for the sake of using it. We have to make sure technology remains only a tool in achieving our educational purposes and does not take over the class.

Human beings have always learned hand in hand with other humans, it has always been this way, and some believe that technology might compromise this magical connection created between teacher and learner, one of the best things in our educational system. Therefore, the role of the teacher is of "undeniable significance" (Obilişteanu \& Niculescu, 2015). Romano also (2003) argues that the traditional, fundamental role of the teacher should remain uncompromised, the same as surgeons and airline pilots continue to be central figures in their systems, where technology is fully integrated.

\section{Video in Foreign Languages Classes}

This section discusses the positive features of using videos in the foreign language classroom and the way we can engage students outside the class with the help of videos and also it emphasizes the teacher's role in the successful use of a video.

The use of videos in teaching foreign languages has become a common feature. There are plenty of videos on the internet that teachers can use to add a special dimension to the learning experiences in order to stimulate students' interest. Therefore, one of the main reasons of using videos is the increased level of interest and motivation shown by most students when watching and generating discussion and different activities related to the video. The video is not just a visual but also an audio material, thus students have the opportunity to hear and see the language. They can observe the way intonation matches facial expression and all the paralinguistic features of the authentic language and consequently they gain a deeper understanding of the text and implicitly the language. When selected properly, videos offer valuable stretches of authentic language material and allow students to analyse situations far beyond their classroom. For example, when teaching British or American culture and civilization, there are numerous videos comprising different aspects of the culture presented by native people that give students useful insights on the matter. Students can also search and watch the video at home, this way the learning experience expands beyond the classroom and encourages learner independence. The teacher can present and discuss in the classroom a video/tutorial regarding academic presentations and provide the students the link to the video and students can watch it again at home, review the main points and use it to prepare their own academic presentation. Sometimes complex topics, such as political system or elections in a foreign country, can be easily understood through a short educational video.

As we have mentioned above there are plenty of reasons why we should use videos in the foreign language class. However we should also consider the potential problems we encounter when trying to introduce a video. Videos enhance 
students' recollection and comprehension but if we want the learning experience to be effective we have to exploit it and use it together with other instructional methods such as discussions and learning activities. The simple playing of the video is not enough. Teachers should also determine the quality of the video and the viewing conditions. It is important that everybody can see and hear the video clearly. Some teachers use the start and stop button excessively and students get irritated, although sometimes stopping the video could be an instructional method in order to let them predict what happens next. Another thing to take into account is the length of the video. It is mostly agreed that short sequences between one to five minutes are the best option. These are easier to handle and can be highly motivating (Harmer, 2001). However, if we want to use a video of more than five minutes we should divide it into parts and design sufficient activities to keep our students interested. For instance, a video of seven minutes regarding British political system may be divided into three parts: Parliament structure, making laws, and elections and voting.

The video can be a valuable resource within the foreign language class, but only the teacher can harness this resource to design a highly stimulating video-based lesson. Susan Stempleski (2002) emphasizes the key role of the teacher in using a video, arguing that it is the teacher who selects the video, creates the activities that facilitates learning, provides students activities for the previewing, viewing and post viewing a video, raises students' awareness of certain language issues and integrates the video with other parts of the curriculum. A teacher can enhance or destroy a learning activity by the manner he or she introduces the video, so it is the teacher who determines the value of a video.

Although, Stempleski (2002) highlights that there is no one 'right way' of using a video, she presents some guidelines which can help teachers plan a video lesson effectively. Students need to learn to appreciate the value of a video, which is often associated with leisure and entertainment. The teacher could ask the students to focus on the gestures and the nonverbal signs used by the people in the video or listen to the intonation of the voices in order to gain a deeper understanding of the material. Teachers should integrate the video as part of a course and not use it as a supplementary material. For instance, at the seminar 'Army branches and ranks', after the students familiarized, through different activities, with Romanian Army branches I have used a video of US Army branches to introduce the American branches and to compare them to the Romanian ones. Thus, it was easier for students to become acquainted with the US Army branches. As we have already mentioned, it is mostly agreed we should use short videos ( 3 to 5 minutes) and make the video available for students outside the classroom. Another important suggestion is to familiarize with the video in advance and then present it to the students and to be prepared to replay the video more than once. Finally, Stempleski (2002) mentions the three stages of activity that teachers need to consider when planning a video-based lesson: previewing, viewing and post-viewing. Previewing activities have the role of arousing students' interest, and discuss the students' background knowledge in the topic to ease the video comprehension. Viewing activities require students to concentrate on important aspects of the video or the language used and the post-viewing activities to react to the video or practice more language activities.

In the final part of this section I would like to focus on certain video teaching techniques. Jeremy Harmer (2001) suggests some prediction activities to awake the students' curiosity: silent viewing, freeze frame, partial viewing, pictureless listening and picture or speech. In 'silent viewing' the teacher plays the video without the sound and the students have to guess what the characters are saying; during the 'freeze frame' the teacher stops the video and requires students to think at what will 
happen next; 'partial viewing' allows students to watch only a part of the screen; 'pictureless listening' allows students to hear but they cannot see the video; and 'picture or speech' divides the class in two, half of the students will look at the screen and half will turn back; the students who see the screen have to describe what is happening to the others.

Another technique that increases the effectiveness of a video is to ask students to think about their background knowledge of a topic and what they think would happen in a particular situation and after that they explain their predictions, they watch the video and then they discuss their predictions and their thoughts. Discussions regarding the content of the video are also very common. Teachers can also solicit students to vote in response to an opinion question, and after playing the video ask them to vote again and compare the two polls (http://cte. cornell.edu/teaching-ideas/teaching-withtechnology/video.html).

The video can be a useful tool to enrich the learning environment, however we should not forget that it is only a technology for delivering content, not a 'body of content in itself' (Brophy, 2003), consequently we should consider carefully when and how we can use the video productively, and to pay close attention to the selection and creation of video-based activities.

\section{Conclusions}

Teachers, learners and technology should form a lasting meaningful alliance. Having identified the positive and the negative impacts of integrating information communication technologies in teaching and learning foreign languages, and also the importance of the teacher's role in educational process, and the bond that creates between teacher and learner, I argue that we cannot forget the past and the years of research of good teaching practices developed by skilled teachers and researchers, but at the same time we cannot ignore the reality beyond the classroom walls. I agree with the view according to which the educational system needs no revolution, i.e. no sudden, radical or complete change, but a skilful evolution, that will assure a continuity and stability to the learning environment. We should carefully build and develop this 'technohumanistic' system based on what it already exists.

\section{REFERENCES}

Bates, A.W. \& Poole, G. (2003). Effective teaching with technology in higher education: Foundations for success. San Francisco, CA: Jossey-Bass.

Brophy, J. (2003). Discussion. In Brophy, J. (Ed.). Advances in Research on Teaching. Using Video in Teacher Education, Volume 10, pp. 287-304, (Adobe Digital Edition Version).

Dragomir, I., Niculescu, B. \& Poşa, O. (2014). Online Courses - a SWOT Analysis. Proceedings II of the $20^{\text {th }}$ International Scientific Conference KBO, pp. 563-567, Sibiu, Romania: "Nicolae Bălcescu" Land Forces Academy Publishing House.

Harmer, J. (2001). The practice of English language teaching. Harlow, UK: Pearson Education.

Korlotyan, D. (2015). New Technologies in Learning English. Retrieved from https://prezi.com/d4ehdwyeqla5/new-technologies-in-learning-english.

Marcinek, A. (2014). Technology and Teaching: Finding a Balance. Retrieved from http://www.edutopia.org/blog/technology-and-teaching-finding-balance-andrew-marcinek.

Mihăilă-Lică, G., Fleischer, W. \& Palea, L. (2015). Considerations on Recruiting and Retaining University Teachers. Proceedings II of the $21^{\text {st }}$ International Scientific Conference KBO, p. 328, Sibiu, Romania: "Nicolae Bălcescu” Land Forces Academy Publishing House. 
Obilişteanu, G. \& Niculescu, B. (2015). Teacher Control in the Second Language Classes. Proceedings II of the $21^{\text {st }}$ International Scientific Conference KBO, pp. 338-343, Sibiu, Romania: "Nicolae Bălcescu" Land Forces Academy Publishing House.

Pritchard, A. (2007). Effective teaching with internet technologies. London, UK: Paul Chapman Publishing.

Romano, M. (2003). Empowering Teachers with Technology. Making it happen. Lanham, US: The Scarecrow Press - Rowman \& Littlefield.

Stempleski, S. (2002). Video in the ELT Classroom: The Role of the Teacher. In J. Richards, \& W. Renandya, (Eds.), Methodology in Language Teaching. An Anthology of Current Practice, pp. 364-367, Cambridge: Cambridge University Press.

https://en.wikibooks.org/wiki/ICT in Education/Definition of Terms, 25.05.2016.

http://cte.cornell.edu/teaching-ideas/teaching-with-technology/video.html, 10.05.2016. 